ISSN: 0377-6395
e-ISSN: 2651-4214
DETERİNER HEKİMLER DERNEĞं

DOI: $10.33188 /$ vetheder.519658

Araştırma Makalesi / Research Article

\title{
Ticari bir dezenfektanın broyler üretim kümeslerindeki etkinliğinin belirlenmesi
}

\author{
Güzin IPLIKKÇİÖ̆LU ÇIL ${ }^{1, a *}$, Bahar ONARAN ${ }^{1, b}$, Ufuk Tansel ŞİRELI I,c \\ ${ }^{1}$ Ankara Üniversitesi, Veteriner Fakültesi, Gıda Hijyeni, ve Teknolojisi Bölümü, Dışkapı, Ankara, Türkiye \\ ORCID: 0000-0001-6897-8222 ${ }^{a}$; 0000-0002-3515-7548 ${ }^{b}$;0000-0001-6180-0755 ${ }^{c}$
}

MAKALE BILGISİ /
ARTICLE
INFORMATION:
Geliş / Received:
30 Ocak 19
30 January 19
Kabul / Accepted:
14 Mart 19
14 March 19
Anahtar Sözcükler:
Broyler
Dezenfeksiyon
Dezenfektan
Hijyen
Keywords:
Broiler
Disinfectant
Disinfection
Hygiene

ÖZET:

Etkili ve yeterli bir sanitasyon programı kanatlı yetiştiriciliğinde biyogüvenliğin kritik adımlarından biridir. Çalışmanın amacı, perasetik asit, hidrojen peroksit ve didesil dimetil amonyum klorit içeren yeni bir ticari dezenfektanın, kümes dezenfeksiyonunda etkinliğinin belirlenmesidir. Çalışma 3 farklı kümeste yürütülmüştür. Kümeslerden biri kontrol grubu olarak kullanılmış ve dezenfeksiyonu \%16’lı gluteraldehit ile yapılmıştır. Diğer iki kümeste ise ticari dezenfektan üreticinin önerisi doğrultusunda uygulanmıştır. Dezenfeksiyon yapılmadan önce temizlikten 24 saat sonra, dezenfeksiyondan sonra, civciv girişinden önce ve civciv girişinden sonra olmak üzere yetiştirmenin farklı dönemlerinde örnekleme yapılmıştır. Üretim tipi ve üretim için kritik görülebilecek yerler dikkate alınarak kümes içerisindeki farklı noktalardan svap tekniği ile örnekler alınmıştır. Örnekler aerob genel canlı, koliform, Enterobacteriaceae, koagulaz pozitif Staphylococccus, Salmonella spp. ve E. coli yönünden analiz edilmiştir. Dezenfeksiyon sonrası çoğu noktada 2-4 $\log$ arası düşüşlerin olduğu gözlenmiştir. Kümeslerde koagulaz pozitif Staphylococcus ve Salmonella spp.'ye rastlanmamıştır. Sonuç olarak dezenfektanın kümeslerde istenilen seviyede hijyeni sağlayabildiği ancak fakat üç farklı kümesteki hijyenik koşullar arasında bir fark olmadığı ortaya konmuştur.

\section{Determination of the effectiveness of a commercial disinfectant in broiler production houses}

\begin{abstract}
:
An effective and adequate sanitation program is one of the critical steps in biosecurity in poultry farming. The aim of this study was to control the hygienic conditions of the broiler houses which's disinfection was made with a commercial disinfectant contains peracetic acid, hydrogen peroxide and didesil dimethyl ammonium chloride. The study was conducted in 3 different broiler houses. One of the broiler houses was used as a control group and disinfection was made with $16 \%$ gluteraldehyde. In the other two broiler houses commercial disinfectant was used according to the manusfacturers recommendation. Samples were taken from different periods of breeding; 24 hours after cleaning before disinfection, after disinfection before chicks arrival and after chicks arrival. Svap samples were taken from different points in the house considering the places that can be critical for the production. Aerobic bacteria, coliform, Enterobacteriaceae, coagulase positive Staphylococccus, Salmonella spp. and E. coli were analyzed from the samples. It was observed that there were 2-4 log decreases at most points after disinfection also, no coagulase positive Staphylococcus and Salmonella spp. were detected. According to the results, commercial disinfectant was found to be effective but there was no difference detected between the hygienic conditions of the three broiler houses.
\end{abstract}

How to cite this article: Çil Gİ, Onaran B, Şireli UT: Ticari bir dezenfektanın broyler üretim kümeslerindeki etkinliğinin belirlenmesi. Vet Hekim Der Derg, 90 (2): 92-97, 2019. DOI: 10.33188/vetheder.519658

\footnotetext{
* Sorumlu yazar / Corresponding author

e-posta adresi / e-mail address: iplikcioglu@ veterinary.ankara.edu.tr
} 


\section{Giriş}

Broyler kümeslerinin temizlik ve dezenfeksiyonu hayvan hastalıklarının ve zoonozların kontrolü ve önlenmesi açısından çiftlik hijyeni yönetiminin en kritik aşamalarındandır. Özellikle gelişmiş ülkelerde artan entansif hayvan yetiştiriciliğinde yönetim uygulamalarının bir parçası olan dezenfeksiyona verilen önem giderek artmaktadır. Buna ek olarak temizlik ve dezenfeksiyon proseslerinin hem işletme hem de ülke ekonomisi açısından kayda değer etkilerinin olduğu da bilinmektedir $(1,2)$.

Tavuklarda, başta kuluçka olmak üzere, yetiştirme ve nakil dönemlerinde başlayan kontaminasyon, kesimhane ve sonrasındaki tüm üretim aşamaları boyunca devam etmektedir. Broyler piliçler, vücutlarında yüksek düzeyde mikroorganizma taşıyarak kesimhaneye gelmektedir. Bu durum, kesim ve işleme prosesleri sırasında karkas kontaminasyonunu büyük ölçüde etkilemektedir. Bu nedenle, düşük kontaminasyonda, güvenilir ve uzun raf ömürlü tavuk eti üretimi için hayvanların yetiştirilme koşulları, kesimhane ve ürün işleme koşulları kadar önem taşımaktadır $(3,4)$.

Etkili ve yeterli bir sanitasyon programı kanatlı yetiştiriciliğinde biyogüvenliğin kritik adımlarından biridir. Bir temizlik ve dezenfeksiyon programı piliçler kümesten kesime gittikten sonra ve yeni civcivlerle doldurulmadan önce dikkatli bir şekilde uygulanmalıdır. Bu amaçla broyler kümeslerinde kullanılan birçok dezenfektan bulunmaktadır. Kullanılan dezenfektanların etkinlik düzeyinin bakteriyel kontaminasyona ve organik madde varlığına bağlı olduğu bilinmektedir. Organik madde bulunmayan ortamlarda dezenfektanların etkinliği oldukça yüksekken, organik madde varlığında etkinlik düzeyi oldukça düşük olmaktadır. Organik madde varlı̆̆ında dezenfektanların etkinliğinin belirlenmesinde çeşitli laboratuvar testleri kullanılmakta fakat saha uygulamaları sırasında dezenfektanların bu yüzeylerdeki etkinliklerinin oldukça düşük olduğu belirtilmektedir $(5,6)$.

Günümüzde kanatlı patojenlerine karşı temizlik ve dezenfeksiyonun ana noktalarının daha da geliştirilmesi yanında, daha ekonomik, çevreye daha duyarlı ve hatta spesifik mikroorganizmalara karşı etkili yeni dezenfektanların üretimine odaklanılmaktadır. Çiftlik bazındaki değerlendirmeler ve birçok temizlik protokolünün karşılaştırılması, üreticilere en uygun temizlik ajanlarının belirlenmesinde, zoonoz hastalıkların engellenmesinde ve patojen mikroorganizmalarının elimine edilmesinde yardımcı olacaktır (7).

Çalışmanın amacı, perasetik asit, hidrojen peroksit ve didesil dimetil amonyum klorit içeren yeni bir ticari dezenfektanın, kümes dezenfeksiyonunda etkinliğinin belirlenmesidir.

\section{Gereç ve Yöntem}

\section{Kümesler ve dezenfeksiyon}

Çalışma Ankara'da, bulunan 3 farklı kümeste gerçekleştirilmiştir. Kümeslerden biri kontrol grubu (A) olarak kullanılmış ve dezenfeksiyonu \%16’lık gluteraldehid ile yapılmıştır. Diğer kümeslerde ise (B, C) perasetik asit, hidrojen peroksit ve didesil dimetil amonyum klorit içeren ticari bir preperat üreticinin önerdiği şekilde kullanılarak dezenfeksiyon işlemi gerçekleştirilmiştir.

\section{Örnekleme planı ve örneklerin tipi}

Örneklemede dezenfeksiyondan önce ve sonra olmak üzere farklı dönemlerde numuneler alınmıştır. Bu dönemler; 1. dezenfeksiyon yapılmadan önce temizlikten 24 saat sonra 2. dezenfeksiyondan sonra, civciv girişinden önce, 3. civciv girişinden sonra şeklindedir. Çalışma süresince, örnekler her bir kümesin 22 farklı iç noktasından alınmış ve örnekleme planı Tablo 1'de gösterilmiştir. Ayrıca çiftlikteki dokuz farklı dış noktadan (bariyerler, tahıl ambarı, dış yüzeyler vb.) ve personelden de örnek alınmıştır. Tüm örneklemlerde svap tekniği kullanılmıştır. Toplamda 279 adet örnek incelenmiştir. Örnek alınacak noktaların seçiminde üretim tipi ve üretim için kritik görülebilecek yerler dikkate alınmıştır. Zemin, duvar, suluk ve havalandırma fanları gibi noktalar kontaminasyon yönünden kritik olarak kabul edilmektedir (8). 
Tablo 1: Örnekleme planı

Table 1: Sampling plan

\begin{tabular}{|c|c|c|c|c|c|c|c|c|c|c|}
\hline & \multicolumn{4}{|c|}{ 1. Kümes } & \multicolumn{2}{|c|}{ 2. Kümes } & \multicolumn{4}{|c|}{ 3. $\quad$ Kümes } \\
\hline & $\begin{array}{c}1 . \\
\text { dönem }\end{array}$ & $\begin{array}{c}2 . \\
\text { dönem }\end{array}$ & $\begin{array}{c}3 . \\
\text { dönem }\end{array}$ & $\begin{array}{c}1 . \\
\text { dönem }\end{array}$ & $\begin{array}{c}2 . \\
\text { dönem }\end{array}$ & $\begin{array}{c}3 . \\
\text { dönem }\end{array}$ & $\begin{array}{c}1 . \\
\text { dönem }\end{array}$ & $\begin{array}{c}2 . \\
\text { dönem }\end{array}$ & $\begin{array}{c}3 . \\
\text { dönem }\end{array}$ & \\
\hline İç mekan & 22 & 22 & 22 & 22 & 22 & 22 & 22 & 22 & 22 & \\
\hline Dış mekan & 9 & 9 & 9 & 9 & 9 & 9 & 9 & 9 & 9 & \\
\hline Toplam & 31 & 31 & 31 & 31 & 31 & 31 & 31 & 31 & 31 & 279 \\
\hline
\end{tabular}

\section{Örneklerin analizi}

Örnekler laboratuvara soğuk zincirde ulaştırılmıştır. Svapların her birine $10 \mathrm{ml}$ tamponlanmış peptonlu su (OXOİD CM 509, Hampshire, England) eklenmiştir. Ekimler, seri dilüsyonlar hazırlanarak, klasik kültür yöntemiyle yapılmıştır. Her mikroorganizma için uygun inkübasyon yöntemi sonrası koloni sayımı gerçekleştirilmiştir. Hijyenik durumu belirlemek için aerobik genel canll, koliform, Enterobacteriaceae ve koagulaz pozitif Staphylococccus sayımları yapılmıştır. Bunun yanı sıra, tavuklarda bulunabilecek önemli patojenlerden Salmonella spp. ve E. coli analizi de yapılmıştır. Toplam aerobic bakteri sayımı için Plate Count Agar (Oxoid CM0325 Hampshire, England), koliformlar için Violet Red Bile Lactose Agar (Oxoid CM 0107 Hampshire, England), Enterobacteriaceae için Violet Red Bile Glucose Agar (Oxoid CM 0485 Hampshire, England), Staphylococcus spp. için Baird-Parker agar (Oxoid CM 0275) besiyerleri kullanılmıştır. Koagulaz testiyle, Staphylococcus spp. identifiye edilmiştir. Salmonella izolasyonu ve identifikasyonu için ISO 6579 yöntemi kullanılmıştır (9).

\section{Bulgular}

Çalışmanın gerçekleştirildiği 3 farklı kümesin iç noktalarından alınan örneklerden elde edilen aerobik genel canlı, koliform ve Enterobacteriaceae sayım sonuçları Tablo 2, 3 ve 4'de gösterilmiştir. Kümeslerde koagulaz pozitif Staphylococcus ve Salmonella spp.'ye rastlanmamıştır. Yalnızca civciv giriş zamanında C kümesinde kapı kolundan 1 adet Biyotip I E. coli izolatı elde edilmiştir. Bu durumun civciv giriş süresinde personel hijyenindeki bir dikkatsizliğin sonucu olduğu düşünülmektedir. Dış mekan ve personel numulerinde önemli bir sonuç elde edilmemiştir bu nedenle veriler gösterilmemiştir. Sonuçlara göre, ticari dezenfektanın etkili olduğu belirlenmiş fakat 3 farklı kümesteki hijyenik koşullar arasında bir fark elde edilmemiştir.

Tablo 2: Temizlikten 24 saat sonra, dezenfeksiyondan öncesi sonuçları

Table 2: Results of 24 hours after cleaning, before disinfection

\begin{tabular}{|c|c|c|c|c|c|c|c|c|c|}
\hline & \multicolumn{3}{|c|}{ Aerob Genel Canlı (log) } & \multicolumn{3}{|c|}{ Koliform $(\log )$} & \multicolumn{3}{|c|}{ Enterobacteriacea $(\log )$} \\
\hline & A & $\mathrm{B}$ & $\mathrm{C}$ & A & $\mathrm{B}$ & $\mathrm{C}$ & A & $\mathrm{B}$ & $\mathrm{C}$ \\
\hline Fan & 0 & 2,78 & 2,78 & 0 & 0 & 0 & 0 & 0 & 2,3 \\
\hline Flap A & 5,9 & 8,55 & 3,95 & 0 & 4,6 & 0 & 06,0 & 4,6 & 2,3 \\
\hline Flap B & 6,8 & 4,76 & 6,47 & 0 & 0 & 0 & 2,3 & 0 & 5,78 \\
\hline Mini Fan A & 6,0 & 4,6 & 4,6 & 0 & 0 & 0 & 0 & 3,78 & 3,3 \\
\hline Kanal girişi & 8,2 & 8,6 & 7,41 & 4,6 & 1,4 & 4,3 & 4,9 & 3,3 & 3,14 \\
\hline Zemin & 5,0 & 5,9 & 0 & 5,9 & 0 & 0 & 4,3 & 3,5 & 0 \\
\hline Dış Kapı kolu (Dış yüzey) & 8,3 & 7,78 & 8,9 & 0 & 0 & 4,78 & 6,2 & 7,07 & 4,68 \\
\hline D1ş Kapı kolu (İç yüzey) & 7,13 & 4,6 & 7,07 & 3,6 & 0 & 0 & 4,78 & 3,3 & 6,0 \\
\hline Duvar & 6,38 & 0 & 6,2 & 0 & 0 & 0 & 0 & 0 & 3,78 \\
\hline Merdiven & 7,18 & 7,9 & 8,0 & 0 & 0 & 5,3 & 6,78 & 7,3 & 3,6 \\
\hline Kapak-1 & 7,07 & 6,07 & 3,0 & 0 & 0 & 0 & 4,0 & 3,78 & 0 \\
\hline Kapak-2 & 3,6 & 2,3 & 3,78 & 0 & 0 & 0 & 0 & 0 & 0 \\
\hline Suluk & 7,14 & 7,9 & 6,2 & 0 & 0 & 0 & 2,9 & 5,6 & 4,78 \\
\hline Yemlik & 7,6 & 2,6 & 5,6 & 0 & 0 & 0 & 4,78 & 0 & 5,6 \\
\hline İç kapı kolu & 5,25 & 0 & 0 & 0 & 0 & 0 & 3,7 & 0 & 0 \\
\hline Yükleme Kapısı & 8,3 & 7,78 & 7,0 & 5,14 & 0 & 0 & 3,6 & 7,0 & 6,3 \\
\hline Flap C & 4,6 & 7,07 & 7,2 & 0 & 0 & 0 & 0 & 5,3 & 6,0 \\
\hline Minifan B & 3,0 & 4,78 & 6,0 & 0 & 0 & 0 & 0 & 0 & 5,07 \\
\hline
\end{tabular}


Tablo 3: Dezenfeksiyondan sonra ve civciv girişinden önce sonuçlar

Table 3: Results of after disinfection, before chicks arrival

\begin{tabular}{llllllllll}
\hline & \multicolumn{3}{l}{ Aerob Genel Canlı $(\log )$} & \multicolumn{3}{l}{ Koliform $(\log )$} & \multicolumn{3}{c}{ Enterobacteriacea $(\log )$} \\
\hline & $\mathrm{A}$ & $\mathrm{B}$ & $\mathrm{C}$ & $\mathrm{A}$ & $\mathrm{B}$ & $\mathrm{C}$ & $\mathrm{A}$ & $\mathrm{B}$ & $\mathrm{C}$ \\
\hline Zemin & 6,92 & 7,3 & 6,7 & 0 & 5,34 & 0 & 3,78 & 5,3 & 6,62 \\
Diş Kapı kolu (Dış yüzey) & 3,2 & 4,71 & 4,3 & 0 & 0 & 0 & 0 & 0 & 0 \\
Diş Kapı kolu (İ̧̧ yüzey) & 5,83 & 5,84 & 5,78 & 0 & 0 & 0 & 0 & 0 & 0 \\
Flap A & 5,41 & 0 & 5,0 & 0 & 0 & 0 & 0 & 0 & 2,6 \\
Flap B & 5,07 & 0 & 4,3 & 0 & 0 & 0 & 0 & 0 & 0 \\
Zemin & 7,3 & 6,85 & 4,14 & 0 & 0 & 0 & 7,2 & 0 & 4,0 \\
Duvar & 6,3 & 4,9 & 5,6 & 0 & 0 & 0 & 6,14 & 0 & 0 \\
Merdiven & 7,21 & 6,38 & 7,04 & 0 & 0 & 5,6 & 5,25 & 0 & 0 \\
Isıtıcı & 0 & 0 & 0 & 0 & 0 & 0 & 0 & 0 & 0 \\
Suluk & 6,6 & 6,73 & 0 & 0 & 0 & 0 & 0 & 5,2 & 0 \\
Yemlik & 0 & 4,6 & 0 & 0 & 4,3 & 0 & 0 & 4,0 & 0 \\
İç kapı kolu & 4,6 & 0 & 2,3 & 0 & 0 & 0 & 0 & 0 & 0 \\
Yükleme kapısı & 7,3 & 0 & 7,6 & 0 & 0 & 0 & 0 & 0 & 0 \\
Flap C & 5,64 & 4,9 & 5,9 & 0 & 0 & 0 & 0 & 0 & 4,41 \\
Minifan & 5,5 & 3,9 & 0 & 0 & 0 & 0 & 0 & 0 & 0 \\
\hline
\end{tabular}

Tablo 4: Civciv girişinden sonra sonuçlar

Table 4: Results of after chicks arrival

\begin{tabular}{llllllllll}
\hline & \multicolumn{3}{l}{ Aerob Genel Canlı $(\log )$} & \multicolumn{3}{l}{ Koliform $(\log )$} & \multicolumn{3}{l}{ Enterobacteriacea $(\log )$} \\
\hline & $\mathrm{A}$ & $\mathrm{B}$ & $\mathrm{C}$ & $\mathrm{A}$ & $\mathrm{B}$ & $\mathrm{C}$ & $\mathrm{A}$ & $\mathrm{B}$ & $\mathrm{C}$ \\
\hline Fan & 0 & 0 & 3.66 & 0 & 0 & 4,2 & 0 & 0 & 0 \\
Flap A & 4,0 & 3,14 & 3.98 & 0 & 0 & 4,2 & 0 & 2,3 & 0 \\
Flap B & 0 & 3,53 & 4,14 & 0 & 0 & 4,2 & 0 & 0 & 2,3 \\
Mini Fan A & 4,14 & 4,78 & 4,53 & 0 & 0 & 4,2 & 0 & 3,78 & 0 \\
Kanal girişi & 6,82 & 4,9 & 7,44 & 4,6 & 0 & 4,2 & 0 & 4,44 & 6,75 \\
Zemin & 8,41 & 4,6 & 7,5 & 4,9 & 0 & 4,2 & 4,25 & 0 & 6,68 \\
Diş Kapı kolu (Dış yüzey) & 2,3 & 2,9 & 4,3 & 0 & 0 & 4,2 & 0 & 0 & 0 \\
Diş Kapı kolu (İç yüzey) & 6,3 & 0 & 6,25 & 0 & 0 & 4,2 & 6,2 & 0 & 0 \\
İç kapı kolu & 3,14 & 3,44 & 3,3 & 0 & 0 & 4,2 & 0 & 0 & 3,3 \\
Duvar & 3,9 & 0 & 2,3 & 0 & 0 & 4,2 & 2,6 & 0 & 0 \\
Merdiven & 4,96 & 6,07 & 0 & 0 & 0 & 4,2 & 0 & 0 & 0 \\
Kapak-1 & 6,25 & 6,13 & 5,6 & 0 & 0 & 4,2 & 0 & 3,3 & 4,3 \\
Kapak-2 & 3,0 & 2,3 & 3,3 & 0 & 0 & 4,2 & 0 & 0 & 0 \\
Isitıcı & 0 & 0 & 4,3 & 0 & 0 & 4,2 & 0 & 0 & 0 \\
Suluk & 6,41 & 0 & 6,73 & 0 & 0 & 4,2 & 2,78 & 0 & 0 \\
Yemlik & 4,0 & 0 & 4,3 & 0 & 0 & 4,2 & 0 & 0 & 0 \\
Yükleme Kapısı & 0 & 4,84 & 2,9 & 0 & 0 & 4,2 & 0 & 0 & 0 \\
Yükleme kapı kolu & 0 & 6,41 & 7,6 & 0 & 0 & 4,2 & 0 & 2,3 & 5,78 \\
Flap C & 7,61 & 3,71 & 6,6 & 0 & 0 & 4,2 & 6,89 & 2,6 & 0 \\
Minifan B & 2,6 & 2,9 & 2,9 & 0 & 0 & 4,2 & 0 & 0 & 0 \\
\hline
\end{tabular}




\section{Tartışma ve Sonuç}

Dezenfektanların bakteriler üzerine etkinliğini kümes şartlarındaki birçok faktörün etkilediği bilinmesine rağmen, çalışmada yapılan dezenfekiyonun ve kullanılan dezenfektanın iyi sonuç verdiği aerobik genel canlı, koliform ve Enterobacteriaceae yönünden yapılan değerlendirmeler ile ortaya konulmuştur. Yapılan bir çalışmada temizlik işlemi sonrası yüzeylerdeki toplam bakteri sayısında ortalama 1-2 log, dezenfeksiyon işlemi sonrası ise 3-4 log düzeyinde azalma tespit edildiği bildirilmiştir (10). Bu araştırmada da benzer şekilde, özellikle dezenfeksiyon sonrası çoğu noktada 2-4 log arası düşüşlerin olduğu gözlenmiştir.

Koskova ve ark.'nın (8) yaptığı benzer bir çalışmada, perasetik asit içeren bir dezenfektanın bir kanatlı kümesinde, dezenfeksiyon öncesi ve sonrası farklı noktalardan svapla alınan numunelerden yapılan ekimler ile etkinliği araştırılmıştır. Perasetik asit dezenfeksiyonu sonrası başlangıç kontaminasyonunun en yüksek olduğu zemin dışındaki tüm noktalarda iyi sonuçlar elde edildiği bildirilmiştir. Araştırıcılar hiçbir noktada koliform tespit edilmediğini ancak küf düzeyinin 160 ile $200 \mathrm{CFU}$ arasında olduğunu ortaya koymuşlardır.

Farklı dezenfaktanların hindi kümeslerindeki Salmonella kontaminasyonu üzerine etkinliğinin karşılaştırıldığı bir çalışmada, formaldehit, glutaraldehit ve kuaterner amonyum bileşiklerinin bir karışımını içeren ürünlerin, hidrojen peroksit ve perasetik asit içeren ürünlerden önemli ölçüde daha iyi performans gösterdiği sonucuna varılmıştır. Çalışmada temizlik ve dezenfeksiyon sonrasında kümeslerin \%68'inde en az 1 Salmonella pozitif örnek saptandığı bildirilmiştir (11).

Logan ve Bartlet (12) yaptıkları çalışmada temizlik ve dezenfeksiyon işleminin ardından organik kirlerin bulunduğu yüzeylerde daha düşük arınma olduğunu bildirmişlerdir. Benzer şekilde, bu çalışmada da fan gibi paslanmaz çelik yüzeylere kıyasla, kanal girişi ve zemin gibi organik atıkların biriktiği yerlerde daha yüksek kontaminasyon düzeylerinin tespit edildiği görülmektedir. Yüzey karakterleri, temizlik ve dezenfeksiyon, test yöntemleri arasındaki ilişkinin araştırıldığı bir çalışmada, yüzey kontaminasyon derecesinin ortamda çalışılan materyalle yakından ilişkili olduğu ortaya konmuştur (13). Mueller-Doblies ve ark.'nın (10) farklı dezenfektanların etkinliğinin araştırıldığı çalışmasında da örneklem noktalarından folluk ve giriş salonunda dezenfektanların en az etkili olduğu belirlenmiştir.

Çalışmada, sadece temizlik işleminin mikroorganizma eliminasyonu üzerine yeterli olmadığı görülmektedir. Benzer şekilde Ramesh ve ark. (14) deterjanlı temizlik işleminde bütün mikroorganizmaların elimine edilmesinin mümkün olmadığını göstermişlerdir. Diğer bir çalışmada ise, kümselerde temizlik sonrası yapılan ekimlerde mikroorganizma sayısının ortalama \%84 düştüğü, bu değerin dezenfeksiyon sonrası \% 99.9'a kadar ulaştı̆g bildirilmiştir (8).

Entansif sistemler kullanarak yoğun ve sürekli bir biçimde üretim yapan gelişmiş ticari işletmeler mikroorganizmalar için mükemmel üreme ortamlarına dönüşmektedir. Kümeslerdeki yönetim, yetiştirme ve bakım sırasında mikrobiyal kontaminasyonun önlenmesi yetiştiricilikteki temel unsurlardandır (15). Bu çalışma saha şartlarında ticari bir dezenfektanın etkinliğini ölçmek amacıyla yapılmış ve etkinlik kümeslerde uygulanan dezenfeksiyon sonrası mikrobiyolojik analizler ile test edilmeye çalışılmıştır. Sonuçlar dezenfektanın kümeslerde istenilen seviyede hijyeni sağlayabildiğini göstermektedir. Dezenfektanların etkinliğinin belirlenmesinde in vitro çalışmalar yanında saha çalışmalarının da yapılması gerektiği de çalışmanın önemli bir sonucudur. Ayrıca elde edilen veriler, dezenfektanların etkinliğinde temizlik ve dezenfeksiyon işlemleri zincirinin birlikte uygulanmasının etkili olduğunu da ortaya koymaktadır.

\section{Kaynaklar}

1. Smith S, Messam LLMV, Meade J, Gibbons J, McGill K, Bolton D, Whyte P (2016): The impact of biosecurity and partial depopulation on Campylobacter prevalence in Irish broiler flocks with differing levels of hygiene and economic performance. Infect Ecol Epidemiol, 6, 31454.

2. Taylor NM, Wales AD, Ridley AM, Davies RH (2016): Farm level risk factors for fluoroquinolone resistance in E. coli and thermophilic Campylobacter spp. on poultry farms. Avian Pathol, 45(5), 559-568.

3. Mead GC (2000) Fresh and further-processed poultry. Microbiol Saf Qual Food. 1, 445-471. 
4. Djeffal S, Mamache B, Elgroud R, Hireche S, Bouaziz O (2018): Prevalence and risk factors for Salmonella spp. contamination in broiler chicken farms and slaughterhouses in the northeast of Algeria. Vet World, 11(8), 1102.

5. Gehan ZM, Anwer W, Amer HM, EL-Sabagh IM, Rezk A, Badawy EM (2009): In vitro efficacy comparisons of disinfectants used in the commercial poultry farms. Int J Poult Sci, 8(3), 237-241.

6. Juan MPA, Claudia, ENG, Alberto PP (2016): Biosecurity Control Systems in Two Phases for Poultry Farms. World Acad Sci, 10 (7), 424-429.

7. Doyle MP, Erickson MC (2006): Reducing the carriage of foodborne pathogens in livestock and poultry. Poult Sci, 85, 960-973.

8. Kaskova A, Ondrasovicova O, Vargova M, Ondrasovic M, Venglovsky J (2007): Application of Peracetic Acid and Quarternary Ammonium Disinfectants as a Part of Sanitary Treatment in a Poultry House and Poultry Processing Plant. Zoo Pub Health, 54(3-4), 125-130.

9. International Standart ISO 6579 (2002): Microbiology of food and animal feeding stuffs — Horizontal method for the detection of Salmonella spp.

10. Gibson H, Taylor JH, Hall KE, Holah JT (1999): Effectiveness of cleaning techniques used in the food industry in terms of the removal of bacterial biofilms. J Appl Microbiol, 87, 41-48.

11. Mueller-Doblies D, Carrique-Mas JJ, Sayers AR, Davies RH (2010): A comparison of the efficacy of different disinfection methods in eliminating Salmonella contamination from turkey houses. J Appl Microbiol, 109(2), 471479.

12. Logan M, Bartlet S (2001): Evaluation of coliform removal at $1 / 2$ inch depth of poultry house floor using Impact-S process. Virginia:Environ Dyn, $\mathbf{4 1} \mathrm{p}$.

13. Moore G, Griffith C (2002): A comparison of traditional and recently developed methods for monitoring surface hygiene within the food industry: An industry trial. Int J Environ Health Res, 12(4), 317-29.

14. Ramesh N, Joseph SW, Carr LE, Douglass LW, Wheaton FW (2002): Evaluation of Chemical Disinfectants for the Elimination of Salmonella Biofilms from Poultry Transport Containers. Poult Sci, 81, 904-910.

15. Barbalho TCF, Almeida PF, Almeida RCC, Hofer E (2005): Prevalence of Listeria spp. at a poultry processing plant in Brazil and a phage test for rapid confirmation of suspect colonies. Food Cont, 16(3), 211-216. 